\title{
Immunohistochemical expression of P53 and Ki-67 on epithelial tumors of ovary
}

\author{
Ipsita Mohapatra $^{1}$, Nikku Harshini ${ }^{2}$, Subha Ranjan Samantaray ${ }^{2 *}$, K. Anantha Sahitya ${ }^{3}$
}

\begin{abstract}
${ }^{1}$ Department of Obstetrics and Gynaecology, All India Institute of Medical Sciences, Kalyani, West Bengal, India ${ }^{2}$ Department of Obstetrics and Gynaecology, ${ }^{3}$ Department of Pathology, Prathima Institute of Medical Sciences, Karimnagar, Telangana, India
\end{abstract}

Received: 29 December 2020

Accepted: 04 Feberuary2021

\author{
*Correspondence: \\ Dr. Subha Ranjan Samantaray, \\ E-mail: drsubha2009@gmail.com
}

Copyright: ( ) the author(s), publisher and licensee Medip Academy. This is an open-access article distributed under the terms of the Creative Commons Attribution Non-Commercial License, which permits unrestricted non-commercial use, distribution, and reproduction in any medium, provided the original work is properly cited.

\begin{abstract}
Background: Ovarian cancer is the third most common gynaecologic cancer and it is well known for its late presentation at advanced stage. Epithelial tumors of the ovary (EOT) are commonest of all ovarian neoplasms and their malignant forms represent about $90 \%$ of ovarian cancers. The determination of cell proliferation has been reported to be of diagnostic and prognostic significance. Over expression of p53 and Ki-67 has been claimed to be a marker of poor prognosis in epithelial ovarian tumors. Aim this study was to evaluate the biological significance of p53 and Ki-67 and their antigen expression in epithelial ovarian cancer.

Methods: This is an observational study of 52 cases of ovarian tumors which were diagnosed and operated at Dept of Gynaecology, Prathima institute of medical sciences in South India, between August 2018 to July 2020.

Results: The mean age of diagnosis for benign, borderline and malignant epithelial tumors was 42 years, 49 years, 56years respectively. Most common histological type was serous epithelial tumors (50\%). Highest p53 and Ki-67 immunoreactivity was seen in malignant tumors. Their co-expression was seen in $46.2 \%$ of the cases.

Conclusions: Epithelial tumors and their malignant forms are common ovarian cancers, which are well known for its lethality and late presentation. Immunohistochemical markers p53 and Ki-67 frequently over expressed in epithelial tumors and has a prognostic role in determining the biologic tumor behaviour which further helps in planning the treatment.
\end{abstract}

Keywords: Epithelial ovarian tumor, Immumohistochemistry, Ki-67, p53

\section{INTRODUCTION}

Ovarian cancer is the seventh most common cancer among women and the third most common gynaecologic cancer that ranks after cervical and uterine cancer. ${ }^{1}$

In $2018,184,799$ deaths occurred due to ovarian cancer, accounting for $4.4 \%$ of the entire cancer-related mortality among women and based on Globocan 2018, the age standardised rate (ASR) of ovarian cancer mortality is 3.9. ${ }^{1}$ Major contributing factors for such high mortality are vague symptoms at presentation, silent growth and lack of specific method of screening at early stage, resulting in advanced stage of disease at the time of diagnosis.

Epithelial tumors of the ovary [EOT] account for approximately two-thirds of all ovarian neoplasms and their malignant forms represent about $90 \%$ of ovarian cancers. $^{2}$

Traditionally Epithelial tumors are classified on the basis of histology in to serous $(80 \%)$, mucinous $(5 \%)$, endometrioid (10\%), clear cell $(5 \%)$ and brenner type, which are then further subclassified as benign, borderline and malignant. ${ }^{2}$ Recently it is subdivided with respect to 
morphological and clinical characteristics into type I and type II epithelial cancer. Type I epithelial tumours include low-grade serous, endometrioid, clear cell, mucinous and transitional cell (Brenner) carcinomas. They often present at an early stage, may arise from borderline ovarian tumours or endometriosis and typically have a good prognosis. Type II epithelial tumours comprise high-grade serous carcinoma, undifferentiated carcinomas and malignant mixed mesodermal tumours. ${ }^{3}$ Pathological diagnosis of ovarian cancer is crucial because different histological subtypes have different treatment modalities.

The determination of cell proliferation has been reported to be of diagnostic and prognostic significance as it plays an important role in clinical behaviour and aggressiveness of ovarian tumors. ${ }^{3}$ Innumerable numbers of molecular markers have been investigated by immunohistochemistry. A central transcriptional mediator p53 when mutated and a nuclear non-histone protein Ki-67 over expression has been claimed to be a marker of poor prognosis in epithelial ovarian tumors. ${ }^{4}$ Ki-67 has been correlated with the clinical stage of tumors and may be a promising factor for targeted molecular therapies. ${ }^{5}$

The purpose of this study was to evaluate the biological significance of reactivity of p53 and $\mathrm{Ki}-67$ and their antigen expression in benign cystadenomas, borderline tumors and invasive cystadenocarcinomas.

The Aims and objectives of the study was to assess the expression of p53 and Ki-67 on epithelial tumors of ovary. To evaluate their correlation with histopathological parameters.

\section{METHODS}

This is an observational study of 52 cases of ovarian tumors which were diagnosed and operated at Dept of Gynaecology, Prathima institute of medical sciences in South India, between August 2018 to July 2020.

\section{Inclusion criteria}

All the diagnosed epithelial tumors of ovary of all age groups.

\section{Exclusion criteria}

All the remaining varieties of tumors of ovary.

All the cases fulfilling inclusion criteria are enrolled after obtaining Institutional ethical committee clearance. Informed consent was taken from all the participants before enrolment. The surgical specimens were sent to the department of pathology in containers filled with $10 \%$ formalin solution. Formalin fixed, paraffin-embedded specimens were studied. Sections were cut at a microtome setting of 4 microns and stained with Haematoxylin and Eosin ( $\mathrm{H}$ and $\mathrm{E}$ ) stain. The slides were studied under light microscopy and the finding was documented. Deparaffinized sections were rehydrated through graded alcohol and subjected to pressure cooker antigen retrieval method using Tris EDTA buffer ( $\mathrm{pH}-9$ ) for p53 staining and sodium citrate buffer for Ki-67. The slides were washed with TBS buffer for 3 mins and primary antibody for p53 was used for p53 antigen detection (P53 IS61630 Dako Real Envision detection system) which were further subjected to DAB (3,3'Diaminobenzidine) chromogen staining. Standard streptavidin biotin technique was used for Ki-67 antigen detection with use of MIB-1 antibody [Molecular Immunology Borstel] (Novocastra code no. Ki-67 MM1R7-C) from Novostain Universal Detection Kit (Novocastra code no. RTU-Ki-67-MM1).

\section{Immunohistochemical interpretation}

Positive cells were determined by counting 1000 cells in at least 10HPF (x40) for each case. The distribution of p53 immunoreactivity in epithelial tumors of ovary were quantitatively assessed as - ve $[<10 \%$ cells $], 1+[10-$ $30 \%$ cells], 2+ [30-50\%cells] and 3+ [>50\%] positive cells. The percentage of immunoreactive tumor cell nuclei was expressed as a Labelling index [Ki-67 LI]. The distribution of Ki-67 over expression was quantitatively assessed as - ve $[<1 \%$ cells $], 1+[1-$ $10 \%$ positive cells], $2+[10-20 \%$ positive cells], $3+[>20 \%$ cells]. Positive immunostaining was observed as brown, granular nuclear staining.

\section{Statistical analysis}

Microsoft excel sheet was used to tabulate the collected data, which was additionally analyzed using Statistical Package for Social Sciences (SPSS, version 21). Categorical data was represented as frequencies and percentages. Continuous data was represented as measure of central location. Chi-square and Fischer exact test were used as tests of significance for categorical data. Pvalue $<0.05$ was considered as statistically significant.

\section{RESULTS}

The mean age of diagnosis for benign, borderline and malignant epithelial tumors was 42 years, 49 years, 56 years respectively with a range of 23 to 74 years. The overall mean age of presentation of epithelial tumours was 49 years.

Most common histological type was serous epithelial tumors $(50 \%)$ followed by mucinous tumors $(30.8 \%)$. Benign ovarian tumors constituted $40 \%$ of all cases followed by malignant tumors $(36 \%)$ and borderline tumors $(23 \%)$.

Highest p53 immunoreactivity was seen in malignant tumors $(89.5 \%)$ compared with borderline $(75 \%)$ and benign tumors $(14.3 \%)$. This association of p53 over expression with biological tumor behaviour was found to be statistically significant $(\mathrm{p}<0.05)$. 
Table 1: Distribution of cases according to age group.

\begin{tabular}{|lllll|}
\hline Age & Benign & Borderline & Malignant & Total \\
\hline$\leq \mathbf{3 0}$ & $1(1.9 \%)$ & $0(0 \%)$ & $0(0 \%)$ & $1(1.9 \%)$ \\
\hline $\mathbf{3 0 - 4 0}$ & $8(15.4 \%)$ & $3(5.8 \%)$ & $1(1.9 \%)$ & $12(23.2 \%)$ \\
\hline $\mathbf{4 0 - 5 0}$ & $11(21.2 \%)$ & $3(5.8 \%)$ & $3(5.8 \%)$ & $17(32.7 \%)$ \\
\hline $\mathbf{5 0 - 6 0}$ & $1(1.9 \%)$ & $4(7.7 \%)$ & $10(19.2 \%)$ & $15(28.8 \%)$ \\
\hline $\mathbf{6 0 - 7 0}$ & $0(0 \%)$ & $2(3.8 \%)$ & $3(5.8 \%)$ & $5(9.6 \%)$ \\
\hline$\geq \mathbf{7 0}$ & $0(0 \%)$ & $0(0 \%)$ & $2(3.8 \%)$ & $2(3.8 \%)$ \\
\hline Total & $21(40.4 \%)$ & $12(23.1 \%)$ & $19(36.5 \%)$ & $52(100 \%)$ \\
\hline
\end{tabular}

Table 2: Distribution of cases according to histological type of EOT.

\begin{tabular}{|lllll|}
\hline Type & Benign & Borderline & Malignant & Total \\
\hline Serous & $11(21.2 \%)$ & $8(15.4 \%)$ & $7(13.5 \%)$ & $26(50 \%)$ \\
\hline Mucinous & $7(13.5 \%)$ & $4(7.7 \%)$ & $5(9.6 \%)$ & $16(30.8 \%)$ \\
\hline Endometroid & $2(3.8 \%)$ & $0(0 \%)$ & $5(9.6 \%)$ & $7(13.5 \%)$ \\
\hline Brenner & $0(0 \%)$ & $0(0 \%)$ & $2(3.8 \%)$ & $2(3.8 \%)$ \\
\hline Clear cell & $1(1.9 \%)$ & $0(0 \%)$ & $0(0 \%)$ & $1(1.9 \%)$ \\
\hline Total & $21(40.4 \%)$ & $12(23.1 \%)$ & $19(36.5 \%)$ & $52(100 \%)$ \\
\hline
\end{tabular}

Table 3: Distribution of p53 immunoreactivity in various histological subtypes of EOT.

\begin{tabular}{|c|c|c|c|c|c|}
\hline \multirow{2}{*}{$\begin{array}{l}\text { Histological } \\
\text { subtype }\end{array}$} & \multicolumn{4}{|l|}{ P53 } & \multirow{2}{*}{ Total } \\
\hline & Negative & $1+$ & $2+$ & $3+$ & \\
\hline Benign & $18(85.7 \%)$ & $2(9.5 \%)$ & $1(4.8 \%)$ & $0(0 \%)$ & $21(100 \%)$ \\
\hline Borderline & $3(25 \%)$ & $5(41.7 \%)$ & $3(25 \%)$ & $1(8.3 \%)$ & $12(100 \%)$ \\
\hline Malignant & $2(10.5 \%)$ & $2(10.5 \%)$ & $5(26.3 \%)$ & $10(52.6 \%)$ & $19(100 \%)$ \\
\hline Total & $23(44.2 \%)$ & $9(17.3 \%)$ & $9(17.3 \%)$ & $11(21.2 \%)$ & $52(100 \%)$ \\
\hline
\end{tabular}

Table 4: Histological type of tumor and p53 immunoreactivity.

\begin{tabular}{|llll|}
\hline & P53 immunoreactivity & Positive & Total \\
\hline Serous & Negative & $8(15.4 \%)$ & $22(42.3 \%)$ \\
\hline Mucinous & $14(26.9 \%)$ & $12(23.1 \%)$ & $18(34.6 \%)$ \\
\hline Endometroid & $6(11.5 \%)$ & $4(7.7 \%)$ & $5(9.6 \%)$ \\
\hline Clear cell & $1(1.9 \%)$ & $2(3.8 \%)$ & $3(5.8 \%)$ \\
\hline Brenner & $1(1.9 \%)$ & $2(3.8 \%)$ & $3(5.8 \%)$ \\
\hline Mixed & $1(1.9 \%)$ & $1(1.9 \%)$ & $1(1.9 \%)$ \\
\hline Total & $0(0 \%)$ & $29(55.8 \%)$ & $52(100.0 \%)$ \\
\hline
\end{tabular}

Table 5: Distribution of Ki-67 over expression in various histological subtypes of EOT.

\begin{tabular}{|llllll|}
\hline $\begin{array}{l}\text { Histological } \\
\text { subtypes }\end{array}$ & Ki-67 LI & & & & Total \\
\hline Benign & Negative & $\mathbf{1 +}$ & $\mathbf{2 +}$ & $\mathbf{3 +}$ & $21(100 \%)$ \\
\hline Borderline & $19(90.5 \%)$ & $1(4.8 \%)$ & $1(4.8 \%)$ & $0(0 \%)$ & $12(100 \%)$ \\
\hline Malignant & $1(5.3 \%)$ & $6(50 \%)$ & $4(33.3 \%)$ & $1(8.3 \%)$ & $19(100 \%)$ \\
\hline Total & $21(40.4 \%)$ & $2(10.5 \%)$ & $6(31.6 \%)$ & $10(52.6 \%)$ & $52(100 \%)$ \\
\hline
\end{tabular}

Table 4 described the p53 expression in different types of epithelial tumors. In our study, no significant relationship between histopathological type of epithelial tumors and p53 over expression could be established ( $\mathrm{p}$ value $>0.05$ ).
In the present study, Ki-67 was expressed on $59.6 \%$ of epithelial tumors of ovary. Highest Ki-67 LI [3+] was significantly associated with malignant epithelial tumors $91 \%$ (10 out of 11 ) while majority of the cases $90.5 \%$ (19 
out of 21) with negative immune expression belonged to benign histological subtype. This was found to be statistically significant ( $\mathrm{p}$ value $<0.05$ ).

Table 6 described the Ki-67 expression in different types of epithelial tumors and no significant relationship between histopathological type of epithelial tumors and $\mathrm{Ki}-67$ over expression was observed in this study ( $\mathrm{p}$ value $>0.05)$
Statistically significant correlation was observed between immune expression of both p53 and Ki-67 markers for diagnosis of epithelial tumors ( $p$ value $<0.05$ ); as with high p53 over expression, there was a tendency towards a higher expression of Ki-67. Their co-expression was seen in $46.2 \%$ of the cases.

Table 6: Histological type of tumor and Ki-67 immunoreactivity.

\begin{tabular}{|c|c|c|c|}
\hline & \multicolumn{3}{|l|}{ Ki-67 LI } \\
\hline & Negative & Positive & Total \\
\hline Serous & $11(21.2 \%)$ & $11(21.2 \%)$ & $22(42.3 \%)$ \\
\hline Mucinous & $6(11.5 \%)$ & $12(23.1 \%)$ & $18(34.6 \%)$ \\
\hline Endometroid & $2(3.8 \%)$ & $3(5.8 \%)$ & $5(9.6 \%)$ \\
\hline Clear cell & $0(0 \%)$ & $3(5.8 \%)$ & $3(5.8 \%)$ \\
\hline Brenner & $2(3.8 \%)$ & $1(1.9 \%)$ & $3(5.8 \%)$ \\
\hline Mixed & $0(0 \%)$ & $1(1.9 \%)$ & $1(1.9 \%)$ \\
\hline Total & $21(40.3 \%)$ & $31(59.7 \%)$ & $52(100 \%)$ \\
\hline
\end{tabular}

Table 7: Correlation between p53 and Ki-67 immunoexpression for EOT.

\begin{tabular}{|c|c|c|c|c|}
\hline & & Ki-67 & & \\
\hline & & Positive & Negative & Total \\
\hline & Positive & $24(46.2 \%)$ & $5(9.6 \%)$ & $29(55.8 \%)$ \\
\hline P53 & Negative & $7(13.5 \%)$ & $16(30.8 \%)$ & $23(44.2 \%)$ \\
\hline & Total & $31(59.6 \%)$ & $21(40.4 \%)$ & $52(100.0 \%)$ \\
\hline
\end{tabular}

Table 8: Distribution of Ki-67 LI with FIGO staging for malignant epithelial tumors of ovary.

\begin{tabular}{|lll|}
\hline FIGO Stage & $\mathbf{n = 1 9}$ & Median Ki-67 LI (\%) \\
\hline Stage I & 13 & 32.5 \\
\hline Stage II & 2 & 45.3 \\
\hline Stage III & 3 & 64.4 \\
\hline Stage IV & 1 & 55.1 \\
\hline
\end{tabular}

Out of 19 malignant EOTs which were staged according to FIGO, the highest number of cases belonged to stage 1 (68.4\%) and lowest number of cases to stage IV (5.3\%). Highest median Ki-67 LI was observed in stage III tumors $(64.4 \%)$ followed by stage IV $(55.1 \%)$ and stage I $(32.5 \%)$. Thus, the Ki-67 expression was found to be higher with increasing stages of tumors.

\section{DISCUSSION}

The mean age of presentation of benign, borderline and malignant epithelial tumors of ovary was 42 years, 49 years and 56 years respectively. This can be explained by the fact that accumulation of somatic mutations in cancer driver genes with increasing age is associated with emergence of malignant neoplasms. ${ }^{6}$ Comparable results were observed by Lumina et al and QasimYA et al. ${ }^{7,4}$ Systematic review of 145 articles by Momenimovahed et al. concluded that epithelial ovarian cancer is an agerelated disease, and is considered mainly a postmenopausal disease. Increased incidence of this cancer is more pronounced in women over 65 years of age, with a median age at diagnosis being $50-79$ years. ${ }^{8}$

Most common histological type was serous epithelial tumors $(50 \%)$ followed by mucinous tumors $(30.8 \%)$. Benign ovarian tumors constituted $40 \%$ of all cases followed by malignant tumors (36\%) and borderline tumors $(23 \%)$. Serous tumor was more common in both benign and malignant group which was similar as observed by Laishram $\mathrm{S}$ et al. ${ }^{9}$

Tumor-suppressor p53 gene is located on the short arm of chromosome 17. This acts by suppressing abnormal cell growth at the beginning of the S-phase of the cell cycle. ${ }^{10}$ The mutation and/or over expression of the p53 are the most frequent anomalies described in human cancers. ${ }^{11}$ Studies have shown a correlation between the mutation/over expression of p53 and the patient prognosis with different types of tumors like breast cancer, rectal, intestinal cancer, lung cancer and also ovarian cancer. ${ }^{12}$ The two main methods for studying p53 are sequence analysis and immunohistochemical staining. ${ }^{13}$ 
Wild-type p53 protein has a very short half-life and thus the protein level is too low to be identified immunohistochemically. In contrast, mutant p53 proteins have a longer half-life and can be easily detected by immunohistochemical methods, which identify approximately $90 \%$ of the p53 mutations. $^{13,14}$ In our study, highest p53 immunoreactivity was seen in malignant tumors $(89.5 \%)$ compared with borderline $(75 \%)$ and benign tumors $(14.3 \%)$. This association of p53 over expression with biological tumor behaviour was found to be statistically significant $(\mathrm{p}<0.05)$.

However, among all histopathological types, negative immunoexpression of p53 was noted in $44.2 \%$ of cases, of which $78.3 \%$ (18/23) belonged to benign subtype. Sylvia et al also showed a higher p53 expression in malignant tumors. ${ }^{15}$ Kmet et al found the estimated prevalence of p53 mutation to be $45 \%, 5 \%$, and $1 \%$, for invasive, borderline and benign tumors respectively. ${ }^{16}$

The relationship between p53 mutation/over-expression and the histopathological subtype in ovarian carcinomas is still controversial. ${ }^{17}$ The high incidence of p53 positivity was also reported in serous cystadenocarcinomas by Milner et al and by Gotlier and Berek. $^{18,19}$ In our study, no significant relationship between histopathological type of epithelial tumors and p53 over expression could be found( $p$ value $>0.05$ ).

$\mathrm{Ki}-67$ is a nuclear antigen located on chromosome 10q25, which is only detected in dividing cells (G1-S-G2-M phase) and not in quiescent cells (G0 phase). ${ }^{5}$ The tumor proliferative fraction of ovarian carcinomas has been investigated immunohistochemically by means of antibodies that recognize the nuclear antigen Ki-67 expressed in proliferating cells. This is known to predict disease outcome in many human malignancies. ${ }^{20}$ Gursan $\mathrm{N}$ et al. noticed a significant relationship between high Ki-67 immunoexpression in ovarian neoplasms and disease-free survival. ${ }^{21}$

In the present study, Ki-67 was expressed on $59.6 \%$ of epithelial tumors of ovary. Highest Ki-67 LI [3+] was significantly associated with malignant epithelial tumors $91 \%$ (10 out of 11) while majority of the cases $90.5 \%$ (19 out of 21) with negative immunoexpression belonged to benign histological subtype. This was found to be statistically significant ( $\mathrm{p}$ value<0.05). Gursan et al. demonstrated that the mean $\mathrm{Ki}-67 \mathrm{LI}$ in benign tumors was $14.9 \%$; in borderline tumors $22.8 \%$; in malignant tumors $42.8 \%$ respectively. ${ }^{21}$ When compared with the benign tumors, Ki-67 LI was found to be significantly higher in the malignant counterpart. KI-67 over expression is associated with aggressive cytomorphology of the tumor, vascular invasion, tumor metastasis and poor prognosis. $^{22}$

However, Ki-67 did not show any significant association with histological subtypes as observed by Laishram $\mathrm{S}$ et al. ${ }^{9}$ Similar result was observed in present study.
The higher frequency rate of co-expression (46.2\%) was found between these two immunohistochemical markers, this pattern of association and accordance may indicate that these tumor markers may run aligned in relation to tumor behaviour and similar result has been observed by Gursan et al. ${ }^{21}$

The FIGO staging has been recognized as a salient independent prognostic factor with higher stage reflecting more aggressive tumor biology. Study of Mahadevappa et al., showed statistically significant association $(\mathrm{P}<0.001)$ between Ki-67 expression and FIGO staging; the median Ki-67 LI in FIGO Stage I-IV were 39.7\%, 69.5\%, 70.6\%, and $59.6 \%$, respectively. ${ }^{3}$ Khouja et al. found a correlation between high Ki-67 expression with higher grade, ascites, advanced FIGO stage, and the presence of residual disease after primary surgery. ${ }^{23}$ In our study, highest median Ki-67 LI was observed in FIGO stage III tumor $(64.4 \%)$ followed by stage IV $(55.1 \%)$.

This study is limited by its small sample size and inability to follow up all patients.

\section{CONCLUSION}

Epithelial tumors of the ovary are one of the common ovarian neoplasms and their malignant forms represent about $90 \%$ of ovarian cancers, which is well known for its lethality and late presentation. This emphasizes the need for effective tools towards screening, diagnosis and prognostication.

Immunohistochemical markers p53 and Ki-67 frequently over expressed in epithelial tumors of ovary with maximal expression observed in malignant counterparts. This accentuates their importance in the oncogenesis of epithelial ovarian cancer and suggests a pertinent role in the progression to the invasive phenotype. Both Ki-67 and p53 alterations retain a prognostic role in ovarian tumors. Immunohistochemistry being ancillary to histopathological diagnosis aids in prognostication and comprehension of the biologic tumor behaviour which further helps in modifying treatment plan.

\section{Funding: No funding sources}

Conflict of interest: None declared

Ethical approval: The study was approved by the Institutional Ethics Committee

\section{REFERENCES}

1. Bray F, Ferlay J, Soerjomataram I, Siegel RL, Torre LA, Jemal A. Global cancer statistics 2018: GLOBOCAN estimates of incidence and mortality worldwide for 36 cancers in 185 countries. CA Cancer J Clin. 2018;68(6):394-424.

2. Berek JS, English DP, longacre TA, Friedlander M. Ovarian, Fallopian Tube and Peritoneal Cancer.In: Berek JS, Berek DL. Berek\& Novak's Gynecology. 
16th ed. Philadelphia: Wolters Kluwer; 2019. P.1077-1142.

3. Mahadevappa A, Krishna SM, Vimala MG. Diagnostic and Prognostic Significance of Ki-67 Immunohistochemical Expression in Surface Epithelial Ovarian Carcinoma. J Clin Diagn Res. 2017;11(2):EC08-EC12.

4. Qasim YA, Saeed SZ, Rashid IM. Immunohistochemical Study of P53 and Ki 67 Expression in Surface Epithelial Tumor of the Ovary. Saudi J. Pathol. Microbiol. 2017;2(3):52-9.

5. Li LT, Jiang G., Chen Q, Zheng JN."Ki-67 is a promising molecular target in the diagnosis of cancer (Review)". Molecular Medicine Reports 11.3. 2015: 1566-72.

6. Risques RA, Kennedy SR. Aging and the rise of somatic cancer-associated mutations in normal tissues. PLoS Genet. 2018;14(1):e1007108.

7. Luminita NG, Carmen U, Maria SM. The immunohistochemical expression of P53 and ki-67 in ovarian epithelial borderline tumors. Correlation with clinicopathological factors. Rom J Morphol Embryol. 2012;53(4):967-73.

8. Momenimovahed Z, Tiznobaik A, Taheri S, Salehiniya H. Ovarian cancer in the world: epidemiology and risk factors. Int J Womens Health. 2019;11:287-99.

9. Laishram S, Gupta V, Bhake A, Wankhede A, Agrawal D. To assess the utility of proliferative marker Ki-67 in surface epithelial ovarian tumor. J Datta Meghe Inst Med Sci Univ. 2019;14:6-10.

10. Finlay CA, Hinds PW, Levine AJ. The p53 protooncogene can act as a suppressor of transformation. Cell. 1989;57(7):1083-93.

11. Levine AJ, Momand J, Finlay CA. The p53 tumour suppressor gene. Nature. 1991;351(6326):453-6.

12. de Graeff P, Crijns AP, de Jong S, et al. Modest effect of p53, EGFR and HER-2/neu on prognosis in epithelial ovarian cancer: a meta-analysis. $\mathrm{Br} \mathrm{J}$ Cancer. 2009;101(1): 149-59.

13. Romus, I, Triningsih FX, Mangunsudirdjo S, Harijadi A. Clinicopathology Significance of p53 and p63 Expression in Indonesian Cervical Squamous Cell Carcinomas. Asian Pac J Cancer Prev. 2013;14(12):7737-41.
14. Levesque MA, Katsaros D, Zola P, et al. Mutant p53 protein overexpression is associated with poor outcome in patients with well or moderately differentiated ovarian carcinoma. Cancer. 1995;75:1327-38.

15. Sylvia MT, Kumar S, Dasari P.The expression of immunohistochemical markers estrogen receptor, progesterone receptor, Her-2- neu, p53 and ki-67 in epithelial ovarian tumors and its correlation with clinicopathologic variables. Indian $\mathbf{J}$ Pathol Microbiol. 2012;55(1):33-7.

16. Kmet LM, Cook LS, Magliocco AM. A review of p53 expression and mutation in human benign, low malignant potential, and invasive epithelial ovarian tumors. Cancer. 2003;97(2):389-404.

17. Skirnisdottir I, Sorbe B, Seidal T. P53, bcl-2, and bax: their relationship and effect on prognosis in early stage epithelial ovarian carcinoma. Int $\mathrm{J}$ Gynecol Cancer. 2001;11:147-58.

18. Milner BJ, Allan LA, Eccles DM, et al. P53 mutations is a common genetic event in ovarian carcinoma. Cancer Res. 1993;53:2128-32.

19. Gottlieb WH, Berek JS. Advances in the biology of gynecologic cancer. CurrOpin Oncol. 1994;6:513-8.

20. Hall PA, Levison DA. Review: assessment of cell proliferation in histological material. J Clin Pathol. 1990;43:184-92.

21. Gursan N, Sipal S, Calik M, Gundogdu C. P53, bcl2, ki-67 li (labeling index) status in benign, proliferative, and malignant ovarian surface epithelial neoplasms. Eurasian J Med. 2009;41(1):10-4.

22. Kamal CK, Simionescu CE, Mărgăritescu C, Stepan A. P53 and Ki-67 immunoexpression in mucinous malignant ovarian tumors. Rom J Morphol Embryol. 2012;53(3):799-803.

23. Khouja MH, Baekelandt M, Nesland JM, Holm R. The clinical importance of ki-67, p16, p14, and p57 expression in patients with advanced ovarian carcinoma. Int J Gynecol Pathol. 2007;26:418-25.

Cite this article as: Mohapatra I, Harshini N, Samantaray SR, Sahitya KA. Immunohistochemical expression of P53 and Ki-67 on epithelial tumors of ovary. Int J Reprod Contracept Obstet Gynecol 2021;10:1005-10. 